\title{
The efficacy and safety of inositol supplementation in preterm infants to prevent retinopathy of prematurity: a systematic review and meta-analysis
}

\author{
Yang Du', Yue He${ }^{1}$, Yue-lin Wang' ${ }^{2}$ Jian-guo Zhou ${ }^{1}$ and Chao Chen ${ }^{1 *}$
}

\begin{abstract}
Background: Inositol supplementation has been linked to beneficial effects on reducing the incidence of retinopathy of prematurity (ROP); however, it's controversial. The meta-analysis aimed to check out the efficacy and safety of inositol supplementation in preterm infants for preventing ROP.

Methods: We conducted searches through PubMed, EMBASE, Medline, Cochrane Central Register of Controlled Trials, Cochrane Database of Systematic Reviews, ClinicalTrials.gov website and conference proceedings. Randomized controlled trials comparing inositol supplementation with placebo were included. Two independent reviewers performed screening, review, and extraction. Statistical analysis was performed using R Project.

Results: Six studies (1194 infants) were proved eligible. In comparison with placebo, inositol supplementation revealed no effect on the incidence of severe ROP (relative risk $[\mathrm{RR}]=0.49,95 \%$ confidence interval $[\mathrm{CI}], 0.18-$ 1.32; heterogeneity, $P=.02 ; I^{2}=66 \%$; low quality of evidence [QOE]), mortality ( $R R=1.25,95 \% \mathrm{Cl}, 0.82-1.90$; heterogeneity, $P=.07 ; I^{2}=51 \%$; low $\left.Q O E\right)$, all stages of ROP (RR $=0.98,95 \% \mathrm{Cl}, 0.87-1.11$; heterogeneity, $P=.41 ; 1^{2}=0 \%$; moderate QOE) and other adverse events. Sensitivity analysis showed an increased mortality in the inositol group ( $R R=1.55,95 \% C l, 1.14-2.11$; heterogeneity, $\left.P=.30 ; I^{2}=18 \%\right)$ after removing the study Hallman 1986, and meta-regression showed a significant association between publication year and efficacy of inositol compared with placebo $(\beta=0.1241 ; 95 \% \mathrm{Cl}, 0.0417-0.0026 ; z=2.9527 ; p=.0032)$.
\end{abstract}

Conclusions: Based on current evidence, inositol supplementation showed no significant effect on preventing severe ROP, and exploratory sensitivity analysis showed a trend toward an increase on mortality.

Keywords: Retinopathy of prematurity, Inositol supplementation, Mortality, Meta-analysis

\section{Background}

Retinopathy of prematurity (ROP) is a disorder of the immature retina in premature infants, which possibly leads to impairment of vision and even blindness [1]. With advances in management, the rising survival rate of premature infants has unexpectedly increased the long-term morbidities of premature infants, equivalently [2-6]. Several recent studies revealed that the incidence of ROP has increased greatly in both

\footnotetext{
* Correspondence: chen6010@163.com

${ }^{1}$ Department of Neonatology, Children's Hospital of Fudan University, 399

Wanyuan Road, Minhang District, Shanghai 201102, China

Full list of author information is available at the end of the article
}

developed and developing countries, such as the United States, Sweden, China and India, which means ROP has become a leading cause of childhood blindness [6-9]. Although there has been effective treatments for severe ROP, they are either invasive such as laser treatment or expensive such as anti-VEGF agents [10]. Besides, several studies indicated propranolol might be a potential effective drug for ROP [1113]. However, the quality of the studies was not high and the safety of propranolol remained to be proved.

Inositol is a naturally occurring six-carbon sugar derivative found in most foods including breast milk. It is an important component of surfactant, and exists intracellularly as

(c) The Author(s). 2019 Open Access This article is distributed under the terms of the Creative Commons Attribution 4.0 International License (http://creativecommons.org/licenses/by/4.0/), which permits unrestricted use, distribution, and reproduction in any medium, provided you give appropriate credit to the original author(s) and the source, provide a link to the Creative Commons license, and indicate if changes were made. The Creative Commons Public Domain Dedication waiver (http://creativecommons.org/publicdomain/zero/1.0/) applies to the data made available in this article, unless otherwise stated. 
phosphoinositide [14]. Inositol supplementation increases the amount of saturated phosphatidylcholine in surfactant in infants. Although the mechanism has not been clear, these findings indicated an important role for inositol to infants.

In 1986 and 1992, Hallman et al. reported two trials in which treatment of infants with respiratory distress syndrome with inositol could improve survival rate and reduced the incidence of $\operatorname{ROP}[15,16]$. A Cochrane meta-analysis in 2015 concluded that inositol supplementation potentially reduced preterm death, severe ROP, and severe intraventricular hemorrhage (IVH) [17]. Besides that, another meta-analysis also drew the similar conclusion [18]. However, the results of a recently published large multicenter randomized clinical trial (RCT) didn't support the previous conclusion, which concluded treatment with inositol did not reduce the risk of type 1 ROP or death vs placebo [19]. Given the early termination, the trial was also not formally powered to make a conclusive assessment. Therefore, we performed a systematic review and meta-analysis to determine the efficacy and safety of inositol supplementation in preterm infants for preventing ROP.

\section{Methods}

\section{Study selection}

We included randomized clinical trials that reported the efficacy and safety of applying inositol in the prevention of ROP. Eligible studies should meet the following criteria: (1) Subjects of study were neonates with gestational age less than 32 weeks or birthweight $<2000 \mathrm{~g}$ and without ROP before inclusion. (2) Intervention referred to applying inositol by intravenous injection or oral feeding (including milk additive). (3) Eligible studies should have at least one of the following outcomes: mortality, the incidence of severe ROP or any stage of ROP. (4) Only prospective randomized clinical trials were considered to be included. Observational studies and non-randomized clinical trials were considered for exclusion.

\section{Search strategy}

PubMed, Medline, EMBASE, Cochrane Central Register of Controlled Trials, Cochrane Database of Systematic Reviews, and clinicaltrials.gov website was searched from inception to November 1st, 2018 without language restrictions. Relevant conference proceedings were used to identify additional literature.

We used the following search terms: (preterm OR neonates) AND (inositol OR myo-inositol), and the articles relevant with ROP were screened manually. One author executed the search strategy and another author independently peer-reviewed the strategy. An independent librarian peer-reviewed the strategy.
To identify studies and determine eligibility, two authors independently reviewed titles and abstracts for inclusion, and full manuscripts and further relevant references were examined if necessary. If two authors disagree, a third researcher would participate in the decision discussion.

\section{Data extraction}

The name of author, year of publication, study design and outcomes were extracted from each study. The primary outcomes were (1) incidence of severe ROP (defined as incidence of ROP stage $\geq 3$ or level of ROP meeting criteria for surgical intervention) (2) mortality (defined as mortality related to all neonatal conditions during the whole follow-up period). The secondary outcomes were any stage of ROP, BPD, suspected or proven NEC, surgical NEC, all grade of IVH, severe IVH (grade III or IV), neonatal seizures, hearing impairment (hearing test of one ear or both ears failed).

\section{Risk for Bias}

The quality of included RCTs were assessed by using the Cochrane Collaborative's risk for bias assessment tool [20]. Each evaluator assessed the risk of bias including selection bias (random-sequence generation and allocation implementation), performance bias (blinding of participants and interveners), attrition bias (miss or quit after randomization), detection bias (blinding of outcome evaluations), reporting bias (selective outcome reporting), and other potential bias. Each criterion was assessed by scoring 'low risk for bias, 'high risk for bias', or 'uncertain risk for bias'. Any disagreement was solved by discussion.

\section{Exploration of heterogeneity and statistical analysis}

We used the intention-to-treat principle. Statistical analysis was performed using $\mathrm{R}$ version 3.5.1 (R Project for Statistical Computing) with $\mathrm{R}$ package (meta, metafor, metareg). All outcomes were reported with relative risk (RR) and 95\% confidence interval (CI). We assessed heterogeneity among multiple studies by using $\mathrm{I}^{2}$ method with the $\chi^{2}$ test to calculate $P$ value. If the homogeneity test showed $P>0.1$ and $\mathrm{I}^{2}<50 \%$ and there is high homogeneity in designing between included studies, we performed fixed effect model (MantelHaenszel method) to combine the summary statistics. Since higher $\mathrm{I}^{2}$ value indicated high statistical heterogeneity or there was significant high heterogeneity in designing between included studies, we performed random effect model (DerSimonian-Laird method) to combine the summary statistics. Additionally, we did sensitivity meta-analysis and meta-regression for primary outcomes to explore high heterogeneity. We 
planned to conduct funnel plot analysis and Egger's test to evaluate the possibility of publication bias if the number of studies in an analysis exceeded 10 . The results reported with $95 \% \mathrm{CI}$, and the 5\% level $(P<0.05)$ was considered to indicate statistical significance.

\section{Grading the quality of evidence}

We used the GRADE (Grading of Recommendations Assessment, Development, and Evaluation) approach to evaluate the quality of evidence [21]. RCTs started with an initial rating of high while nonrandomized comparative studies with low. For each outcome, we assessed method limitations of the included studies, precision, directness, consistency, and the likelihood of publication bias.

\section{Results}

\section{Description of the evidence}

The online search identified 1670 articles. After excluding 1607 records by screening the titles, abstracts and trial registries, a total of 63 manuscripts were fully examined (Fig. 1). We finally enrolled 6 randomized clinical trials $[15,16,19,22-26]$ for meta-analysis.
These six RCTs involving a total of 1194 preterm infants with $\mathrm{BW}<2000 \mathrm{~g}$, of which three $[15,16,22-24]$ included 355 preterm infants with respiratory distress syndrome (RDS) and requiring mechanical ventilation, two $[25,26]$ included 201 preterm infants with $23^{0 / 7}$ to $29^{6 / 7}$ weeks GA and one [16] included 638 extremely preterm infants born before $28^{0 / 7}$ weeks of gestation. The main baseline characteristics selected as gestational age and weight, which were well balanced between the inositol and placebo group of all studies. In addition, none of the infants enrolled had major congenital anomalies, eye anomalies, or moribund conditions. All of the trials were finished in the United States.

All premature infants were assigned to the inositol group or placebo group. Three RCTs $[15,19,26]$ supplied inositol or placebo to infants by intravenous injection firstly and then oral feeding with repeat dose (duration from 5 days to 10 weeks). Phelps 2013 [25] injected inositol or placebo intravenously with a single dose in 20 min. Friedman 1995 [23, 24] fed infants with high-inositol formula continuously as intervention and low-inositol formula as placebo control. The trial reported by Hallman in 1986 [15] didn't use surfactant but all of the other five trials $[16,19,22-26]$

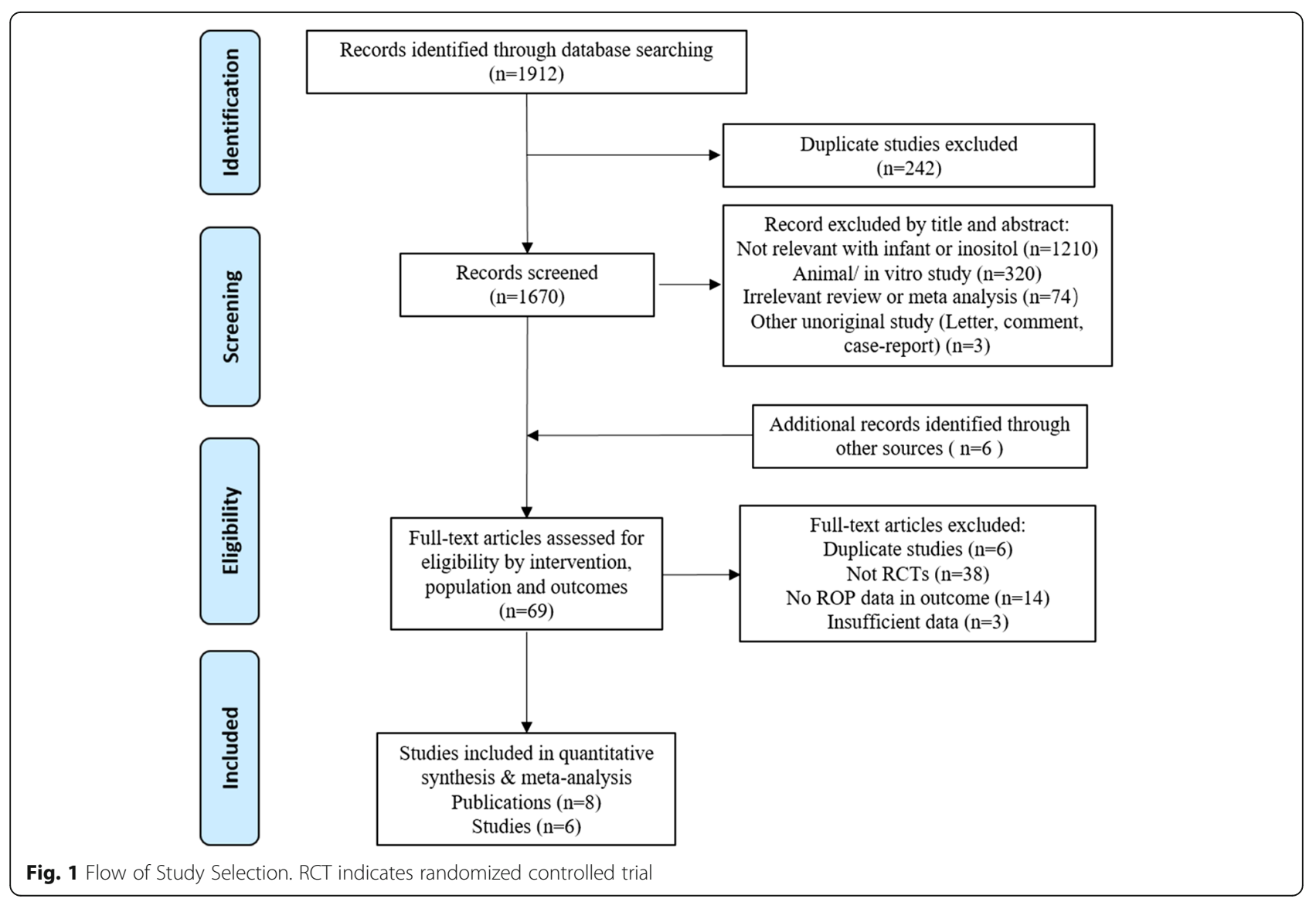


reported surfactant administration. All the six RCTs reported number of neonatal or infant deaths, while five trials $[16,19,23,25,26]$ of which reported number of severe ROP. Number of other complications and adverse events were reported in all or part of these RCTs (Table 1 ).

Among all RCTs, three $[15,16,23]$ didn't clarify the randomization procedure, while the other three $[19,25$, 26] specified the use of a computer-based randomization program that allowed complete concealment of the randomization sequence. Four studies $[15,19,25,26]$ masked all the involved physicians, nurses and ophthalmologists. Implementation of masking was not mentioned in two studies $[16,23]$. Three trials $[19,25,26]$ were registered in a trial registry but the other three [15, $16,23]$ were not. Two studies $[15,16]$ performed interim analysis, which were not registered, and one study [23, 24] had been reported 3 times and the number of neonates enrolled was increasing, which cause high risk of bias. All the RCTs included were assessed by the Cochrane Collaboration's risk for bias assessment tool [20], and three of which were rated as high quality while others were varying, from moderate to low (Table 2).

\section{Primary outcomes \\ Severe ROP}

The primary outcome of this meta-analysis was the incidence of severe ROP. In the inositol group, 47 (9.98\%) of the 471 preterm infants from 5 studies [16, $19,23,25,26$ ] developed severe ROP, compared to 47 (11.01\%) of 427 in the placebo group. The metaanalysis revealed no statistically significant difference among infants who received inositol supplement versus those who received a placebo $(R R=0.49$, D-L random-effects, 95\% CI, 0.18-1.32; heterogeneity, $P=.02 ; \mathrm{I}^{2}=66 \%$; low QOE; Fig. 2, Table 3).

\section{Mortality}

Mortality was reported in six RCTs [15, 16, 19, 24-26], overall mortality was 139 (22.13\%) of the 628 preterm infants in the inositol group versus 85 (15.48\%) of the 549 preterm infants. The results of meta-analysis revealed no statistically significant difference between infants who received inositol supplement versus placebo $(R R=1.25$, D-L random-effects, 95\% CI, 0.82-1.90; heterogeneity, $P=.07 ; \mathrm{I}^{2}=51 \%$; low QOE; Fig. 3, Table 3).

\section{Secondary outcomes}

\section{Any stage of ROP}

Any stage of ROP was reported in four studies $[15,16,19$, 23]. The result showed that 192 of 438 (43.84\%) preterm infants developed ROP in the inositol group versus 213 $(47.23 \%)$ of 451 in the placebo group. The meta-analysis revealed no statistically significant difference among infants who received inositol supplement versus those who received a placebo $(\mathrm{RR}=0.98, \mathrm{D}-\mathrm{L}$ random-effects, 95\% CI, 0.87-1.11; heterogeneity, $P=.41 ; \mathrm{I}^{2}=0 \%$; moderate QOE; Fig. 4, Table 3).

\section{Adverse events}

No statistically significant difference was detected between the inositol and control group on the incidence of $\mathrm{BPD}(\mathrm{RR}=0.95$, D-L random-effects, 95\% CI, 0.721.25 ; heterogeneity, $P=.15 ; \mathrm{I}^{2}=38 \%$; low $\left.\mathrm{QOE}\right)$, suspected or proven NEC ( $R R=0.85$, D-L random-effects, 95\% CI, 0.58-1.24; heterogeneity, $P=.48$; $\mathrm{I}^{2}=0 \%$; moderate $\mathrm{QOE})$, surgical NEC (RR $=0.76, \mathrm{D}$ - $\mathrm{L}$ random-effects, 95\% CI, 0.24-2.38; heterogeneity, $P=.15$; $\mathrm{I}^{2}=48 \%$; moderate QOE), all stage of IVH ( $R R=0.77$, D-L randomeffects, 95\% CI, 0.59-1.00; heterogeneity, $P=.45 ; \mathrm{I}^{2}=0 \%$; moderate QOE), severe IVH (grade III/IV) $(\mathrm{RR}=0.68$, D$\mathrm{L}$ random-effects, 95\% CI, 0.45-1.03; heterogeneity, $P=.17 ; \mathrm{I}^{2}=35 \%$; low $\left.\mathrm{QOE}\right)$, late-onset sepsis $(\mathrm{RR}=1.22$, D-L random-effects, 95\% CI, 0.97-1.54; heterogeneity, $P=.40 ; \mathrm{I}^{2}=0 \%$; low $\left.\mathrm{QOE}\right)$, seizure $(\mathrm{RR}=1.02$, $\mathrm{D}-\mathrm{L}$ random-effects, 95\% CI, 0.41-2.56; heterogeneity, $P=.34$; $\mathrm{I}^{2}=8 \%$; high QOE), hearing impairment $(\mathrm{RR}=1.36, \mathrm{D}-\mathrm{L}$ random-effects, $95 \% \mathrm{CI}$, 0.87-2.31; heterogeneity, $P=.48$; $\mathrm{I}^{2}=0 \%$; high QOE) (See Additional file 1: Figure S1).

\section{Sensitivity analysis and Meta-regression}

We estimated the pooled effect of the primary outcomes of inositol supplement compared with placebo after removing the study Hallman 1986 [15], which was the only study not using surfactant. Without the study, the results of meta-analysis showed an increased mortality in the inositol group, with a risk ratio of 1.55 (D-L random-effects, 95\% CI, 1.14-2.11; heterogeneity, $P=.30 ; \mathrm{I}^{2}=18 \%$ ).

We additionally examined the relationship between publication year and primary outcomes. Meta-regression demonstrated a significant association between publication year and measured efficacy of inositol compared with placebo $(\beta=0.1241 ; \quad 95 \% \quad C I, \quad 0.0417-0.0026 ; \quad \mathrm{z}=2.9527$; $p=.0032$ ) (Fig. 5). However, there was no significant association between publication year and risk ratio of mortality in inositol group compared with placebo group $(\beta=$ 0.0045; 95\% CI, $-0.0382-0.0473 ; \mathrm{z}=0.2081 ; p=.8351$ ) (See Additional file 1: Figure S2).

\section{Discussion}

To our knowledge, this is the most up-to-date metaanalysis to determine the efficacy and safety of inositol supplementation in preterm infants for preventing ROP, and our result has challenged conclusions from previous systematic reviews $[17,18]$. In this metaanalysis, we synthesized the evidence from six RCTs including 1194 preterm infants to describe the effect 


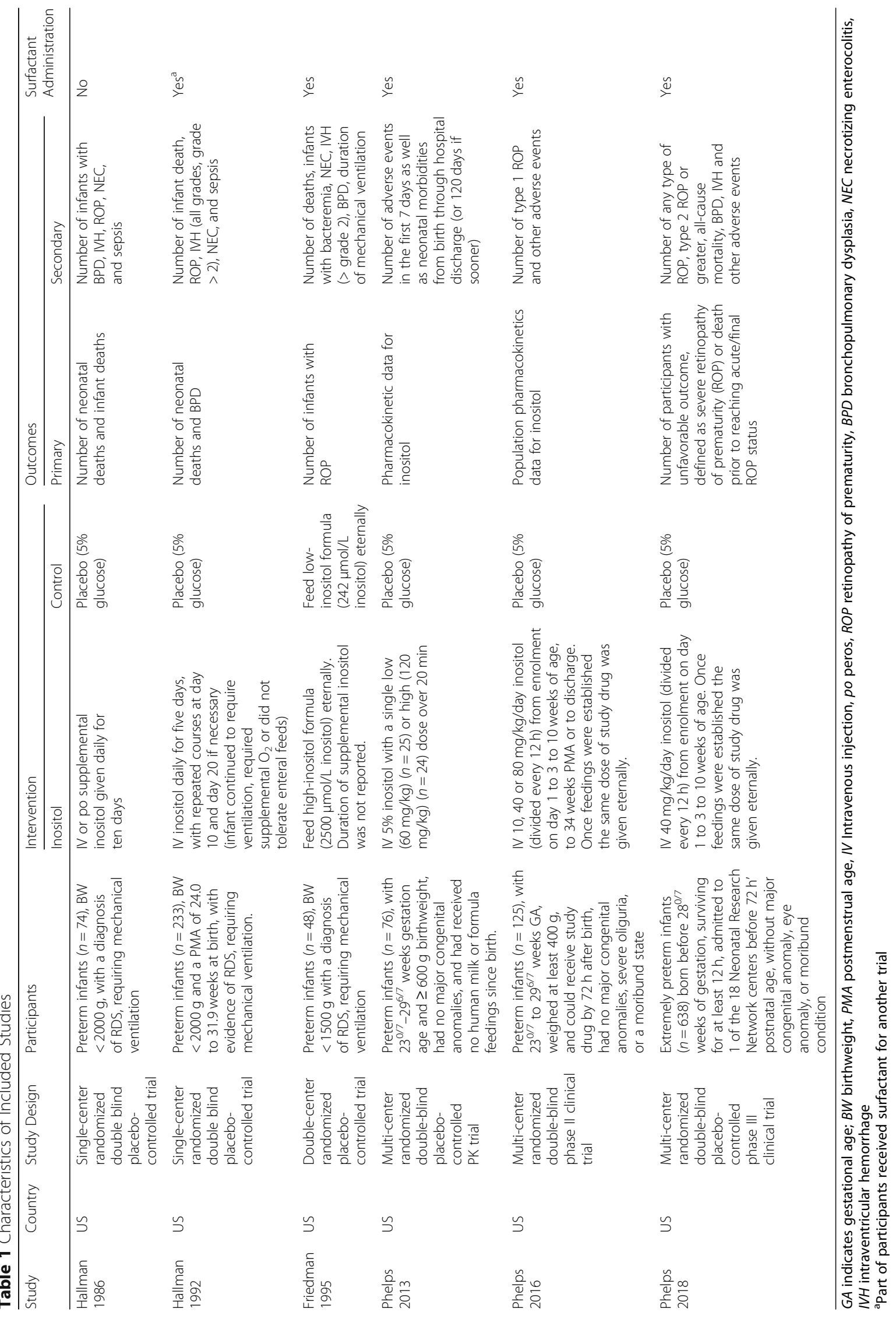


Table 2 Risk of Bias

\begin{tabular}{|c|c|c|c|c|c|c|c|}
\hline \multirow[t]{2}{*}{ Study } & \multicolumn{2}{|l|}{ Selection Bias } & \multirow{2}{*}{$\begin{array}{l}\text { Performance Bias } \\
\text { Blinding of participants } \\
\text { and personnel }\end{array}$} & \multirow{2}{*}{$\begin{array}{l}\text { Detection Bias } \\
\text { Blinding of outcome } \\
\text { assessment }\end{array}$} & \multirow{2}{*}{$\begin{array}{l}\text { Attrition Bias } \\
\text { Incomplete outcome } \\
\text { data addressed }\end{array}$} & \multirow{2}{*}{$\begin{array}{l}\text { Reporting Bias } \\
\text { Selective } \\
\text { reporting }\end{array}$} & \multirow{2}{*}{$\begin{array}{l}\text { Other } \\
\text { Other bias }\end{array}$} \\
\hline & $\begin{array}{l}\text { Random sequence } \\
\text { generation }\end{array}$ & $\begin{array}{l}\text { Allocation } \\
\text { concealment }\end{array}$ & & & & & \\
\hline Hallman 1986 & Unclear & Low & Low & Low & Low & Unclear & High \\
\hline Hallman 1992 & Unclear & Unclear & Low & Unclear & Low & Unclear & High \\
\hline Friedman 1995 & Unclear & Low & Unclear & Unclear & Low & Unclear & High \\
\hline Phelps 2013 & Low & Low & Low & Low & Low & Low & Low \\
\hline Phelps 2016 & Low & Low & Low & Low & Low & Low & Low \\
\hline Phelps 2018 & Low & Low & Low & Low & Low & Low & Low \\
\hline
\end{tabular}

of inositol administration in preterm infants. On the basis of low quality of evidence, we found that inositol has no effect on the incidence of severe ROP and mortality. Inositol has no effect on the incidence of all stage of ROP, BPD, suspected or proven NEC, surgical NEC, all grade of IVH, severe IVH (grade III or IV), neonatal seizures and hearing impairment, either.

Some studies have demonstrated some important biological functions of inositol, including the adjustment of cell osmotic pressure [27], the maturity of nervous system [28], and the synthesis of pulmonary surfactant phospholipid [29], etc. Evidence has shown that inositol was rich in the umbilical artery of embryo [30], suggesting inositol might be one of the basic substances for human growth. Meanwhile, the concentration of inositol was high in human breast milk ( $>1200 \mathrm{mmol} / \mathrm{L}$ ), which means inositol was an important need for infants after birth [31].

However, the results of our meta-analysis didn't support a positive effect of inositol in preventing severe ROP in preterm infants. Our results even concluded that inositol may have a potential trend to increase the mortality of infants, and the heterogeneity among included studies was high. In the early studies $[15,16,23,25,26]$, the results favored the benefits of inositol to prevent severe ROP and other preterm comorbidities, but the beneficial findings were not observed in the last study reported by Phelps 2018 [19]. The meta-analysis and sensitivity analysis might give us some explanations about the high heterogeneity. For the efficacy of inositol decreasing along with the publication year, one explanation could be that inositol may promote surfactant synthesis and function. In the early trials, antenatal steroids and surfactant were not widely used, inositol could reduce the severity of respiratory distress syndrome, and by the way, reduce ROP and other morbidities. However, antenatal steroids, exogenous surfactant, and noninvasive ventilator support have been more and more widely used during the past 30 years [32-34], the use of antenatal steroids and exogenous surfactant have outweighed the benefit of inositol. And the definition severe ROP which needs intervention has changed in the more than 30 years due to the advanced treatment such as laser treatment and anti-VEGF agents. Besides, Phelps 2018 [19] reported a significant increase in mortality has challenged the safety of inositol, opposite to the results of other five small-size studies $[15,16,23,25$, 26] without enough power. Although the result of meta-analysis revealed no statistically significant difference of the mortality between the two groups,

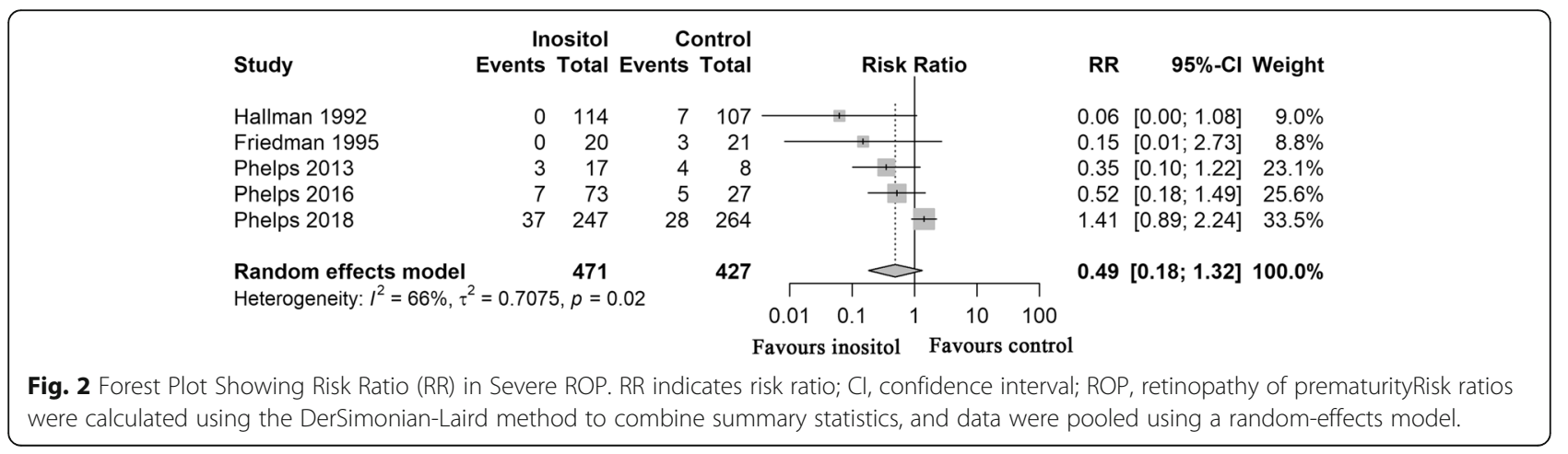


Table 3 GRADE Summary of Findings of Supplemental Inositol Compared to Placebo for Retinopathy of Prematurity

\begin{tabular}{|c|c|c|c|c|c|c|}
\hline \multirow[t]{2}{*}{ Outcomes } & \multicolumn{2}{|l|}{ No. of Cases per 1000 Infants } & \multirow[t]{2}{*}{ RR $(95 \% \mathrm{Cl})$} & \multirow[t]{2}{*}{ Participants, No. } & \multirow[t]{2}{*}{ Studies No. } & \multirow{2}{*}{$\begin{array}{l}\text { Quality of } \\
\text { Evidence }^{b}\end{array}$} \\
\hline & Assumed Risk of Placebo ${ }^{a}$ & $\begin{array}{l}\text { Corresponding Risk of } \\
\text { Supplemental Inositol (95\% Cl) }\end{array}$ & & & & \\
\hline Severe ROP & 110 & $54(19-145)$ & $0.49(0.18-1.32)$ & 898 & 5 & Low $^{c, d}$ \\
\hline Mortality & 155 & $194(127-294)$ & $1.25(0.82-1.90)$ & 1177 & 6 & Low $^{c, e}$ \\
\hline All stage of ROP & 472 & $463(411-524)$ & $0.98(0.87-1.11)$ & 889 & 4 & Moderate $^{\mathrm{e}}$ \\
\hline $\mathrm{BPD}$ & 436 & $414(314-545)$ & $0.95(0.72-1.25)$ & 1099 & 6 & Low $^{c, e}$ \\
\hline Suspected or proven NEC & 88 & $75(51-109)$ & $0.85(0.58-1.24)$ & 1189 & 6 & Moderate $^{\mathrm{e}}$ \\
\hline Surgical NEC & 37 & $28(9-88)$ & $0.76(0.24-2.38)$ & 834 & 3 & Moderate $^{c}$ \\
\hline All stage of IVH & 392 & $302(231-392)$ & $0.77(0.59-1.00)$ & 429 & 3 & Moderate $^{f}$ \\
\hline Severe IVH (grade III/IV) & 174 & $118(78.3-180)$ & $0.68(0.45-1.03)$ & 1179 & 6 & Low $^{c, e}$ \\
\hline Late-onset sepsis & 194 & $236(188-299)$ & $1.22(0.97-1.54)$ & 1141 & 5 & Low $^{c, f}$ \\
\hline Seizure & 26 & $27(11-66)$ & $1.02(0.41-2.56)$ & 833 & 3 & High \\
\hline Hearing impairment & 107 & $146(93-247)$ & $1.36(0.87-2.31)$ & 605 & 3 & High \\
\hline
\end{tabular}

${ }^{\text {a }}$ The basis for the assumed risk (e.g. the median control group risk across studies) is provided. The corresponding risk (and its $95 \% \mathrm{Cl}$ ) is based on the assumed risk in the comparison group and the relative effect of the intervention (and its $95 \% \mathrm{Cl}$ )

${ }^{b}$ The GRADE Working Group grades of evidence are as follows: high quality (further research is very unlikely to change our confidence in the estimate of effect), moderate quality (further research is likely to have an important impact on our confidence in the estimate of effect and may change the estimate), low quality (further research is very likely to have an important impact on our confidence in the estimate of effect and is likely to change the estimate), and very low quality (we are very uncertain about the estimate)

${ }^{c}$ Heterogeneity is highly significant between included trials and hard to be explained

${ }^{\mathrm{d}}$ One trial has high risk of bias and one has unclear risk of bias

'Two trials have high risk of bias and one has unclear risk of bias

${ }^{\mathrm{f}}$ Two trials have high risk of bias

there was a trend toward an increase on mortality of infants in the inositol group. The sensitivity analysis after removing the study Hallman 1986 [15], which was the only study not using surfactant, showed a statistically significant increased mortality in the inositol group. One explanation could be that side effects appeared after the benefit of inositol was outweighed by surfactant. Additionally, the difference of participants, inositol provided for the trials, dose of inositol and the duration of treating might also play a role in the results. For example, the infants included in Phelps 2018 [19] were more immature than the prior studies, and the duration of treating in this study was up to 10 weeks, much longer than the prior studies.

\section{Strengths and limitations}

The strengths of this review include explicit eligibility criteria; a comprehensive search peer-reviewed by a research librarian, with no language restriction; independent assessment of eligibility, data abstraction, assessment of risk of bias, quality of evidence assessment by using the GRADE approach; registration on the PROSPERO website and report followed the QUOROM statement [35], the guidelines for meta-analysis of RCTs. Our meta-analysis updated the Cochrane review published in 2015 [17] and included other two RCTs $[19,26]$ published recently. We also drew a conclusion which is totally different from the previous meta-analysis, which reminded inositol administration cautiously.

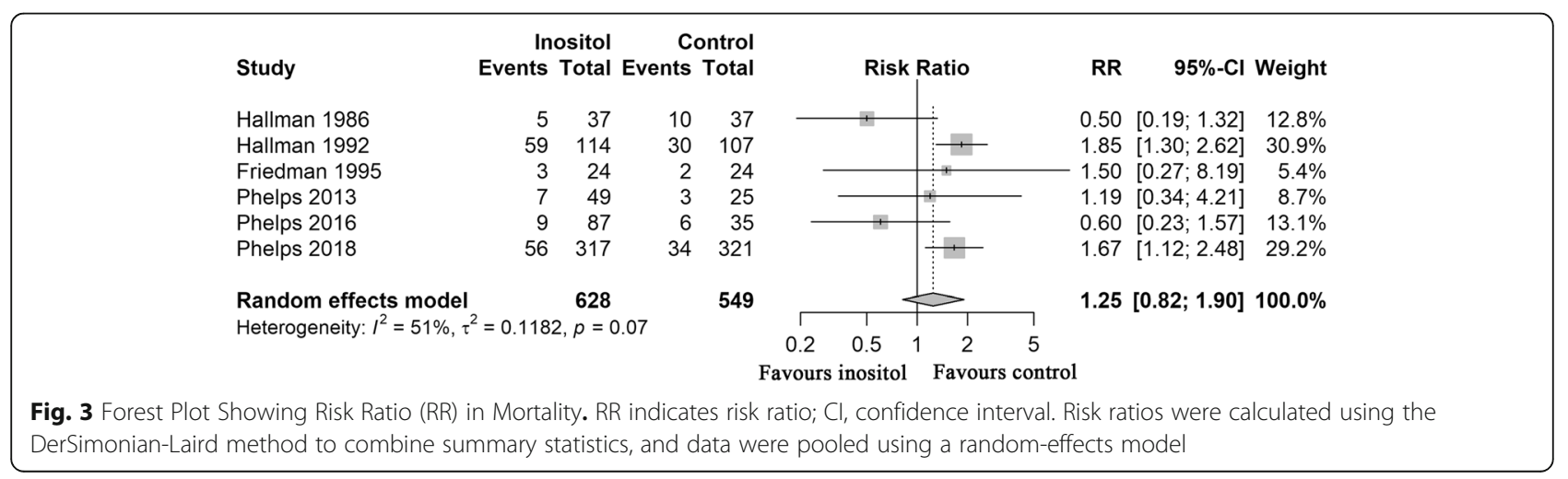




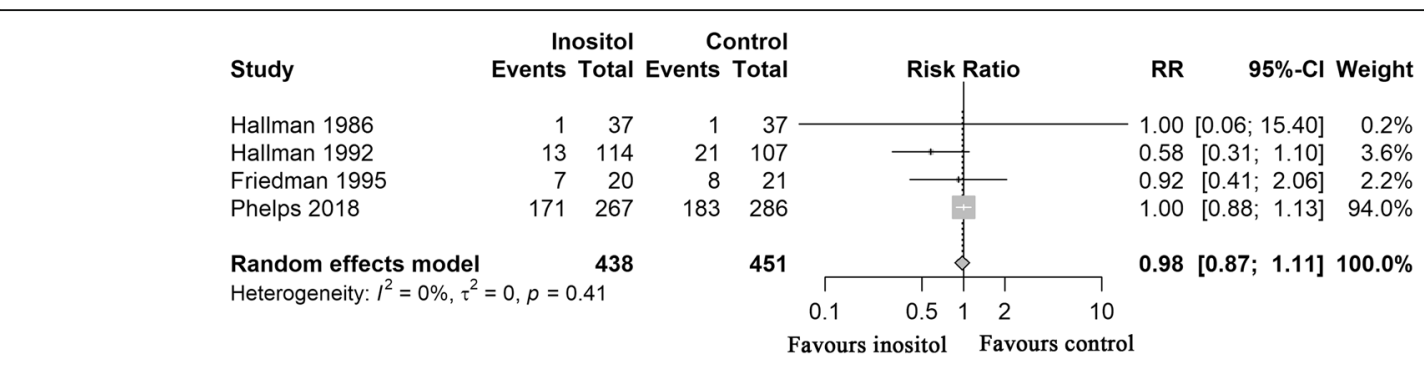

Fig. 4 Forest Plot Showing Risk Ratio (RR) in Any Stage of ROP. RR indicates risk ratio; Cl, confidence interval; ROP, retinopathy of prematurity. Risk ratios were calculated using the DerSimonian-Laird method to combine summary statistics, and data were pooled using a random-effects model

Our meta-analysis also had several limitations. Firstly, only three RCTs were rated as high quality and the other three were varying from moderate to low, which along with the high heterogeneity led to low QOE of primary outcomes. Secondly, we did meta-regression to examine the relationship between publication year and primary outcomes, which had relatively low power when few studies were included in the analysis. Thirdly, we couldn't evaluate publication bias statistically via funnel plot due to the number of trials included were less than ten. Besides, we lacked individual patient data to find out the potential beneficial subgroup. Finally, all the included studies lacked long-term follow-up outcomes, such as visual outcomes and structural outcomes in childhood.

\section{Conclusions}

The present meta-analysis showed that inositol supplementation may have no effect in prevention of severe ROP but a trend toward an increase on mortality in

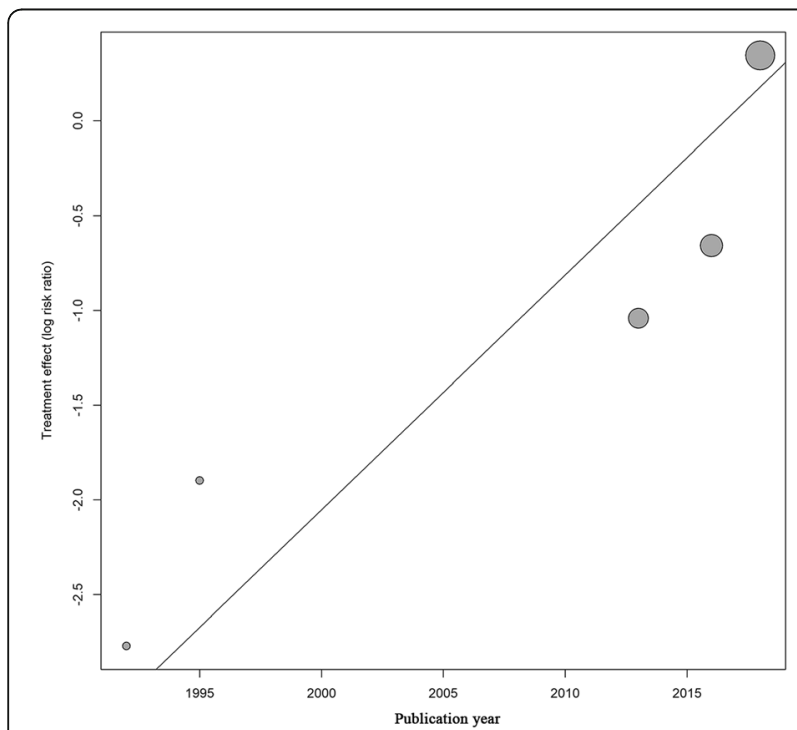

Fig. 5 Bubble Diagram Examining Relationship Between Publication Year and Efficacy of Inositol Compared with Placebo. RR indicates risk ratio preterm infants less than 32 weeks. Routine inositol supplementation to preterm infants should not be recommended based on current evidence.

\section{Additional file}

Additional file 1: Figure S1. Forest Plot Showing Risk Ratio (RR) in Complications and Adverse Event. Figure S2. Bubble Diagram examining Relationship Between Publication Year and Mortality. (DOCX 595 kb)

\section{Abbreviations}

Cl: Confidence interval; QOE: Quality of evidence; RCT: Randomized controlled trial; ROP: Retinopathy of prematurity; RR: Relative risk

\section{Acknowledgements}

We are grateful to Dr. Xiang-yuan Huang and Prof. Wei-li Yan, from Department of Clinical Epidemiology, Children's Hospital of Fudan University, for their assistance of statistical analyses. We thank Dr. Qi-yuan, Zhuang, from Department of neurosurgery, Huashan Hospital, Fudan University, for his review of the manuscript.

\section{Authors' contributions}

The conception and design of the study was provided by all the authors; acquisition of papers, analysis and interpretation were led by CC, DY, HY and WYL and was checked by ZJG; the manuscript was first drafted by DY and $\mathrm{HY}$; all the authors were involved in reviewing the draft. All authors have read and approved the final version of the manuscript. DY and HY contributed equally to this work and should both be considered first authors.

\section{Funding}

No funding was received for this study.

\section{Availability of data and materials}

All data generated or analysed during this study are included in this published article [and its supplementary information files].

Ethics approval and consent to participate

Not applicable.

\section{Consent for publication}

Not applicable.

\section{Competing interests}

The authors declare that they have no competing interests.

\section{Author details}

${ }^{1}$ Department of Neonatology, Children's Hospital of Fudan University, 399 Wanyuan Road, Minhang District, Shanghai 201102, China. ${ }^{2}$ Department of Ophthalmology, Peking Union Medical College Hospital, Beijing, China. 
Received: 25 February 2019 Accepted: 4 June 2019

Published online: 25 June 2019

\section{References}

1. Gilbert C. Retinopathy of prematurity: a global perspective of the epidemics, population of babies at risk and implications for control. Early Hum Dev. 2008:84(2):77-82.

2. Hack M, Wright LL, Shankaran S, et al. Very-low-birth-weight outcomes of the National Institute of Child Health and Human Development neonatal network, November 1989 to October 1990. Am J Obstet Gynecol. 1995; 172(2 Pt 1):457-64.

3. Fanaroff AA, Wright LL, Stevenson DK, et al. Very-low-birth-weight outcomes of the National Institute of Child Health and Human Development neonatal research network, may 1991 through December 1992. Am J Obstet Gynecol. 1995;173(5):1423-31.

4. Stevenson DK, Wright LL, Lemons JA, et al. Very low birth weight outcomes of the National Institute of Child Health and Human Development neonatal research network, January 1993 through December 1994. Am J Obstet Gynecol. 1998;179(6 Pt 1):1632-9.

5. Lemons JA, Bauer CR, Oh W, et al. Very low birth weight outcomes of the National Institute of child health and human development neonatal research network, January 1995 through December 1996. NICHD Neonatal Research Network. Pediatrics. 2001;107(1):E1.

6. Stoll BJ, Hansen $\mathrm{NI}$, Bell EF, et al. Neonatal outcomes of extremely preterm infants from the NICHD neonatal research network. Pediatrics. 2010;126(3): $443-56$.

7. Austeng D, Kallen K, Hellstrom A, et al. Regional differences in screening for retinopathy of prematurity in infants born before 27 weeks of gestation in Sweden--the EXPRESS study. Acta Ophthalmol. 2014;92(4):311-5.

8. Xu Y, Zhou $X$, Zhang Q, et al. Screening for retinopathy of prematurity in China: a neonatal units-based prospective study. Invest Ophthalmol Vis Sci. 2013:54(13):8229-36

9. Dhingra D, Katoch D, Dutta S, Samanta R, Aggarwal K, Dogra MR. Change in the incidence and severity of retinopathy of prematurity (ROP) in a neonatal intensive care unit in northern India after 20 years: comparison of two similar prospective cohort studies. Ophthalmic Epidemiol. 26(3):169-74.

10. Sankar MJ, Sankar J, Mehta M, Bhat V, Srinivasan R. Anti-vascular endothelial growth factor (VEGF) drugs for treatment of retinopathy of prematurity. Cochrane Database Syst Rev. 2016;2:D9734.

11. Filippi L, Cavallaro G, Bagnoli P, Dal Monte M, Fiorini P, Donzelli G, Tinelli F, Araimo G, Cristofori G, la Marca G, et al. Oral propranolol for retinopathy of prematurity: risks, safety concerns, and perspectives. J Pediatr. 2013;163(6): 1570-7.

12. Filippi L, Cavallaro G, Bagnoli P, Dal Monte M, Fiorini P, Berti E, Padrini L, Donzelli G, Araimo G, Cristofori G, et al. Propranolol 0.1\% eye micro-drops in newborns with retinopathy of prematurity: a pilot clinical trial. Pediatr Res. 2017:81(2):307-14

13. Kaempfen S, Neumann RP, Jost K, Schulzke SM. Beta-blockers for prevention and treatment of retinopathy of prematurity in preterm infants. Cochrane Database Syst Rev. 2018;3:D11893.

14. MacFarlane PM, Di Fiore JM. Myo-inositol effects on the developing respiratory neural control system. Adv Exp Med Biol. 2018;1071:159-66.

15. Hallman M, Jarvenpaa AL, Pohjavuori M. Respiratory distress syndrome and inositol supplementation in preterm infants. Arch Dis Child. 1986;61(11):1076-83.

16. Hallman M, Bry K, Hoppu K, Lappi M, Pohjavuori M. Inositol supplementation in premature infants with respiratory distress syndrome. N Engl J Med. 1992;326(19):1233-9.

17. Howlett A, Ohlsson A, Plakkal N. Inositol in preterm infants at risk for or having respiratory distress syndrome. Cochrane Database Syst Rev. 2015;2:D366.

18. Fang $\mathrm{L}$, Sorita A, Carey WA, Colby CE, Murad MH, Alahdab F. Interventions To Prevent Retinopathy of Prematurity: A Meta-analysis. Pediatrics. 2016; 137(4).

19. Phelps $\mathrm{DL}$, Watterberg $\mathrm{KL}$, Nolen $\mathrm{TL}$, et al. Effects of Myo-inositol on type retinopathy of prematurity among preterm infants $<28$ Weeks' gestational age. JAMA. 2018:320(16):1649.

20. Higgins JP, Altman DG, Gotzsche PC, et al. The Cochrane Collaboration's tool for assessing risk of bias in randomised trials. BMJ. 2011;343:d5928.

21. Guyatt GH, Oxman AD, Vist GE, et al. GRADE: an emerging consensus on rating quality of evidence and strength of recommendations. BMJ. 2008; 336(7650):924-6.
22. Hallman M, Pohjavuori M, Bry K. Inositol supplementation in respiratory distress syndrome. Lung. 1990;168(Suppl):877-82.

23. Friedman CA, Temple DM, Robbins KK, Muller CJ, Rawson JE. Randomized controlled trial of high inositol and calorie supplementation in preterm infants at risk for chronic lung and eye disease. In: American Academy of Pediatrics Annual Meeting, vol. 13. San Francisco, California; 1995.

24. Friedman CA, McVey J, Borne MJ, et al. Relationship between serum inositol concentration and development of retinopathy of prematurity: a prospective study. J Pediatr Ophthalmol Strabismus. 2000;37(2):79-86.

25. Phelps DL, Ward RM, Williams RL, et al. Pharmacokinetics and safety of a single intravenous dose of myo-inositol in preterm infants of 23-29 wk. Pediatr Res. 2013;74(6):721-9

26. Phelps DL, Ward RM, Williams RL, et al. Safety and pharmacokinetics of multiple dose myo-inositol in preterm infants. Pediatr Res. 2016;80(2):209-17.

27. Wiese TJ, Dunlap JA, Conner CE, Grzybowski JA, Lowe WJ, Yorek MA. Osmotic regulation of Na-myo-inositol cotransporter mRNA level and activity in endothelial and neural cells. Am J Phys. 1996;270(4 Pt 1):C990-7.

28. Greene ND, Copp AJ. Mouse models of neural tube defects: investigating preventive mechanisms. Am J Med Genet C Semin Med Genet. 2005; 135C(1):31-41.

29. Hallman M, Saugstad OD, Porreco RP, Epstein BL, Gluck L. Role of myoinositol in regulation of surfactant phospholipids in the newborn. Early Hum Dev. 1985;10(3-4):245-54

30. Brusati $V$, Jozwik $M$, Jozwik $M$, et al. Fetal and maternal non-glucose carbohydrates and polyols concentrations in normal human pregnancies at term. Pediatr Res. 2005:58(4):700-4.

31. Cavalli C, Teng C, Battaglia FC, Bevilacqua G. Free sugar and sugar alcohol concentrations in human breast milk. J Pediatr Gastroenterol Nutr. 2006; 42(2):215-21.

32. Saigal S, Doyle LW. An overview of mortality and sequelae of preterm birth from infancy to adulthood. Lancet. 2008;371(9608):261-9.

33. Wang H, Gao X, Liu C, et al. Morbidity and mortality of neonatal respiratory failure in China: surfactant treatment in very immature infants. Pediatrics. 2012;129(3):e731-40

34. Zeitlin J, Manktelow BN, Piedvache A, et al. Use of evidence based practices to improve survival without severe morbidity for very preterm infants: results from the EPICE population based cohort. BMJ. 2016:354:i2976.

35. Moher D, Cook DJ, Eastwood S, Olkin I, Rennie D, Stroup DF. Improving the quality of reports of meta-analyses of randomised controlled trials: the QUOROM statement. Quality of Reporting of Meta-analyses. Lancet. 1999; 354(9193):1896-900.

\section{Publisher's Note}

Springer Nature remains neutral with regard to jurisdictional claims in published maps and institutional affiliations.

Ready to submit your research? Choose BMC and benefit from

- fast, convenient online submission

- thorough peer review by experienced researchers in your field

- rapid publication on acceptance

- support for research data, including large and complex data types

- gold Open Access which fosters wider collaboration and increased citations

- maximum visibility for your research: over $100 \mathrm{M}$ website views per year

At BMC, research is always in progress.

Learn more biomedcentral.com/submissions 